\title{
Recruitment of brown adipose tissue as a therapy for obesity-associated diseases
}

\section{Olivier Boss ${ }^{1}$ and Stephen R. Farmer ${ }^{2}$ *}

1 Energesis Pharmaceuticals, Inc., Cambridge, MA, USA

${ }^{2}$ Department of Biochemistry, Boston University School of Medicine, Boston, MA, USA

\section{Edited by:}

Patrick Seale, University of

Pennsylvania, USA

\section{Reviewed by:}

Jae B. Kim, Seoul National University, South Korea

Miguel Lopez, University of Santiago de Compostela, Spain

*Correspondence:

Stephen R. Farmer, Department of Biochemistry, Boston University

School of Medicine, 72 East Concord

Street, Boston, MA 02118, USA.

e-mail: sfarmer@bu.edu
Brown adipose tissue (BAT) has been recognized for more than 20 years to play a key role in cold-induced non-shivering thermogenesis (CIT, NST), and body weight homeostasis in animals. BAT is a flexible tissue that can be recruited by stimuli (including small molecules in animals), and atrophies in the absence of a stimulus. In fact, the contribution of BAT (and UCP1) to resting metabolic rate and healthy body weight homeostasis in animals (rodents) is now well established. Many investigations have shown that resistance to obesity and associated disorders in various rodent models is due to increased BAT mass and the number of brown adipocytes or UCP1 expression in various depots. The recent discovery of active BAT in adult humans has rekindled the notion that BAT is a therapeutic target for combating obesity-related metabolic disorders. In this review, we highlight investigations performed in rodents that support the contention that activation of BAT formation and/or function in obese individuals is therapeutically powerful. We also propose that enhancement of brown adipocyte functions in white adipose tissue (WAT) will also regulate energy balance as well as reduce insulin resistance in obesity-associated inflammation in WAT.

Keywords: human, brown adipose tissue, BAT, progenitors, recruitment, therapy

\section{BAT MASS/ACTIVITY CAN BE ENHANCED WITH DRUGS, INDUCING LONG-TERM BODY WEIGHT LOSS AND IMPROVEMENT OF DIABETES IN ANIMALS}

The efficacy of increasing brown adipose tissue (BAT) recruitment (BAT mass and expression of UCP1) as a therapeutic approach for obesity and type 2 diabetes has been demonstrated by many groups (Holloway et al., 1992; Himms-Hagen et al., 1994; Kopecky et al., 1995, 1996a; Nagase et al., 1996; Collins et al., 1997; Ghorbani and Himms-Hagen, 1997; Arch, 2002; Kim et al., 2006). Agents that increase BAT recruitment and UCP1 levels (for instance $\beta_{3}$-AR agonists) can effectively treat obesity and insulin resistance/diabetes in all rodent models of obesity (Arch, 2002). Interestingly, in lean animals (which have normal amounts of BAT), enhancement of BAT recruitment or activity (e.g., by drugs or cold exposure) does not affect body weight, and the induced increase in metabolic rate is compensated by an increase in food intake. However, in obese animals enhancement of energy expenditure by BAT recruitment seems to be the most effective (long-term) therapy for decreasing body weight and improving the metabolic status (as compared to treatment with diet drugs). Indeed, increasing or restoring normal levels of BAT mass/UCP1 levels in obese rodents prevents the adaptive drop in metabolic rate invariably observed upon weight loss due to a decrease in food intake (Dulloo and Girardier, 1990; Leibel et al., 1995; Crescenzo et al., 2003; Heilbronn and Ravussin, 2003; Dulloo, 2005, 2007; Major et al., 2007). It seems that increasing BAT mass/UCP1 levels resets the "adipostat" to a lower level (Cannon and Nedergaard, 2009). Weight/fat loss can be maintained long-term only if the adipostat is readjusted to a lower level. The mechanisms participating in this adipostat are not known in detail but BAT (increasing
BAT recruitment/activity) seems to play an important role in this system (Cannon and Nedergaard, 2009). Gastric bypass (Rouxen-Y) surgery has been shown to have dramatic effects on body weight and blood glucose homeostasis/glucose metabolism. The molecular mechanisms responsible for this efficacy are not yet fully understood but recent data suggest that BAT recruitment plays a key role (Stylopoulos et al., 2009), again supporting an adipostat-lowering effect of BAT.

Recently, Almind et al. (2007) showed that the capacity to induce BAT/UCP1 expression around muscles confers resistance to obesity in mice. Similarly, Nagase et al. (1996) showed that treatment of obese yellow KK mice with the $\beta_{3}$-AR agonist CL 316243 decreased the body weight and fat of the mice, and induced expression of UCP1 in skeletal muscle [as well as in BAT and white adipose tissue (WAT)]. Even though the authors contend that the $\beta_{3}$-AR agonist induced UCP1 in myofibers, we can speculate that in fact the UCP1 mRNA detected in the muscle mass indeed originated from induced brown adipocytes around the muscle fibers, and that the "UCP" signal identified with an UCP1 antibody in the myofibers was in fact increased levels of UCP3 (Boss et al., 1997). These results support, in a more physiological setting, earlier results showing that overexpression of UCP1 in WAT of mice can prevent the development of obesity in genetic as well as dietary models of the disease (Kopecky et al., 1995, 1996a,b). In contrast, lack of BAT or UCP1 (at or close to thermoneutrality) induces obesity and diabetes in mice (Lowell et al., 1993; Hamann et al., 1996; Feldmann et al., 2009). Initially, it was hoped that $\beta_{3}$-AR agonists would also enhance energy expenditure in humans but these drugs proved to be ineffective probably due to less than optimal bioavailability and/or pharmacokinetic properties of the 
compounds (Arch, 2002, 2008). Another likely explanation is that, unlike in rodents, in humans the $\beta_{3}-\mathrm{AR}$ is expressed at much lower levels than the $\beta_{1}-A R$ and $\beta_{2}-A R$ in adipose tissues (WAT and BAT; Deng et al., 1996; Arch, 2008). Induction of brown adipocyte formation with drugs in humans, in order to enhance or restore healthy levels of BAT recruitment, is a feasible strategy to enhance energy expenditure but "druggable" molecular targets other than the $\beta_{3}$-AR and PPAR $\gamma$ have yet to be identified (Harper et al., 2004; Ravussin and Kozak, 2004).

\section{RECRUITMENT OF BROWN ADIPOCYTES FROM PROGENITORS}

Various studies have shown that primary preadipocytes isolated from white and brown adipose depots differentiate in vitro into the corresponding white and brown adipocytes (Kopecky et al., 1990; Rehnmark et al., 1990; Ailhaud et al., 1992). Multilocular fat cells, expressing UCP1 and rich in mitochondria, were initially observed in a WAT depot by Young et al. (1984). The emergence of these so-called ectopic brown adipocytes in WAT could be induced by cold acclimation in rats (Cousin et al., 1992, 1996) and mice (Loncar, 1991a,b; Guerra et al., 1998). This phenomenon is generally referred to as recruitment. The new cells were found to be sympathetically innervated (Giordano et al., 1996) and remained in WAT as long as a sympathetic stimulation persisted (Loncar, 1991b). Subsequent reports have shown that administration of selective $\beta_{3}$-AR agonists like CL 316243 in mice could also induce the emergence of brown adipocytes in WAT depots (Nagase et al., 1996; Collins et al., 1997; Ghorbani and Himms-Hagen, 1997; Guerra et al., 1998; Granneman et al., 2005) and that this phenomenon was strongly dependent on the mouse genetic background (Collins et al., 1997; Guerra et al., 1998; Kozak and Koza, 1999). Interestingly, it was discovered that transgenic overexpression of the human $\beta_{1}$-AR in WAT of mice also induced the appearance of abundant brown adipocytes in this tissue (Soloveva et al., 1997). These results suggested that the $\beta_{3}$-AR might not be the only $\beta$ subtype controlling the emergence of brown adipocytes in WAT. These results were recently confirmed using human multipotent adipose-derived stem cells (hMADS; Mattsson et al., 2011). However, administration of $\beta_{1}$-AR agonists would not be appropriate for the treatment of obesity due to the well-known effects of these agents on the heart.

The origin and the true nature of the multilocular cells rich in mitochondria and expressing UCP1 that appeared in WAT upon cold acclimation or $\beta_{3}$-AR stimulation has yet to be determined. The presence of brown adipocyte progenitors in WAT has been hypothesized by studies showing that $10-15 \%$ of the precursor cells isolated from mouse WAT differentiate into brown adipocytes in culture (Klaus et al., 1995) and that brown adipocyte progenitors are present in human WAT depots (Digby et al., 1998). Another hypothesis suggests that a few unilocular white adipocytes are indeed "masked" brown adipocytes that can recover a brown phenotype in response to a SNS stimulation such as that induced by cold exposure. Himms-Hagen et al. (2000), studying the effect of CL 316243 in rats, suggested that the multilocular cells expressing UCP1 that appeared in the WAT were different from the classical brown adipocytes and postulated that they might derive, at least in part, from pre-existing unilocular adipocytes. Orci et al.
(2004) showed that hyperleptinemia in rats induces the transformation of white adipocytes into so-called post-adipocytes (or fat-oxidizing machines), which have the phenotype of brown adipocytes. Other effectors that enhance brown adipocyte recruitment in white depots include synthetic PPAR $\gamma$ ligands such as thiazolidinediones (Wilson-Fritch et al., 2004; Xue et al., 2005; Vernochet et al., 2009; Petrovic et al., 2010). Overall, it seems very likely that, at least in some WAT depots, brown adipocytes can emerge from differentiation of brown adipocyte precursors/preadipocytes or transdifferentiation of existing white adipocytes (Jimenez et al., 2003; Zingaretti et al., 2009). The precise origins of brown cells in WAT will likely be determined within the very near future since recent studies have started to identify the progenitors of brown as well as white adipocytes. In the case of brown cells, tracing the lineages arising from progenitors expressing the myogenic transcription factor, myf5 have clearly shown that brown adipocytes within the interscapular BAT depot of mice share an origin with skeletal myocytes that arise from the dermomyotome (Seale et al., 2008). In these investigations, the brown cells recruited to WAT in response to the cold were myf5 negative, thus unlikely to share a myogenic origin. Two independent studies employing different procedures have identified white progenitors within the microvasculature of adipose tissue and not of other tissues (Rodeheffer et al., 2008; Tang et al., 2008). These progenitors express markers of mural cells (pericytes) that arise from the sclerotome and give rise to several other cell types of the vasculature. It is conceivable; therefore, that recruitment of WAT brown adipocytes is due to a selective activation of these mural cells to progress along a brown lineage in response to effectors that are activated by the recruitment-associated stimulus. Possible effectors include BMP7, which has been shown to induce the conversion of mesenchymal stem cells to brown adipocytes in culture and is required for BAT formation in mice (Tseng et al., 2008).

\section{HUMAN ADULTS HAVE FUNCTIONAL, ACTIVATABLE BAT}

Understanding the importance of BAT in energy balance has entered a new and exciting era of investigation now that the existence and functionality of this tissue in adult humans has convincingly been demonstrated (Heaton, 1972; Rothwell and Stock, 1979; Hany et al., 2002; Cohade et al., 2003; Bar-Shalom et al., 2004; Cannon and Nedergaard, 2004). Early studies by Rothwell and Stock (1979) using infrared thermography resulted in data strongly suggesting that adult humans possess functional BAT that is activated by ephedrine. The authors suggested that if this tissue contributes to diet-induced thermogenesis as it does in animals it could play an important role in energy balance and body weight homeostasis. It is unfortunate that it took almost 30 years, and many studies using more recent techniques, for the research community to accept that adult humans have physiologically significant amounts of BAT, and that defective recruitment or activity of this tissue may contribute to weight gain and insulin resistance.

The new data show that adult humans have appreciable amounts of BAT, that the metabolic activity or rather, glucose uptake activity is activated by cold, and that the amount of BAT in individuals is inversely correlated (independently) to body weight and age (Celi, 2009; Cypess et al., 2009; Farmer, 2009; Saito et al., 2009; Yoneshiro et al., 2011). A role for BAT in regulating human 
body weight homeostasis is strongly suggested by the numerous reports that found the amount of BAT (detected by PET) in individuals is inversely correlated to body weight, independent of age, and other factors.

The capacity of BAT to be recruited in humans, as in animals, is convincingly supported by the following data: (a) The existence of a reservoir of brown adipocyte/BAT progenitor cells in human muscle (CD34+) and WAT depots (hMADS; Crisan et al., 2008; Elabd et al., 2009); (b) Cold stimulates BAT activity and energy expenditure (thermogenesis) in humans (Huttunen et al., 1981; Cohade et al., 2003; Garcia et al., 2004, 2006; Christensen et al., 2006; Nedergaard et al., 2007; Saito et al., 2009; Van Marken Lichtenbelt et al., 2009); (c) Pheochromocytoma, a catecholaminesecreting tumor of the adrenal gland, has long been shown to cause increases in BAT mass and metabolic rate as well as leanness (Ricquier et al., 1982; Lean et al., 1986; Cannon and Nedergaard, 2004; Fukuchi et al., 2004; Ramacciotti et al., 2006). When the pheochromocytoma tumor is eliminated the high metabolic rate (BAT) subsides (Ramacciotti et al., 2006).

The recent discovery of brown adipocyte stem/progenitor cells (Crisan et al., 2008; Elabd et al., 2009) in skeletal muscle and subcutaneous WAT of adult humans, further supports a physiological role for BAT in humans. The fact that these progenitor cells have been found in older adults as well as in fetal tissues strongly suggests that enhancing BAT recruitment, in order to restore BAT mass to a healthy level, is feasible in humans of any age.

\section{BROWN ADIPOCYTE PROGENITORS IN HUMANS}

A major hurdle in identifying (and validating) novel drug targets for brown adipocyte recruitment is the lack of large quantities of relevant and unmodified (non-immortalized) human brown adipocytes in culture to allow for screening of small molecules as well as other applications. Stroma-vascular cell preparations from human BAT (or other tissues like skeletal muscle or WAT) contain only very limited quantities of cells (if any at all) that can differentiate into brown adipocytes. The recently identified human brown adipocyte stem/progenitor cells, CD34+ in skeletal muscle (Crisan et al., 2008), and hMADs in subcutaneous WAT (Elabd et al., 2009), could provide the means to search for novel molecular targets as well as validate existing candidate targets for the development of therapeutics to increase brown adipocyte/BAT recruitment and $\mathrm{UCP} 1$ levels in vivo. Both $\mathrm{CD} 34+$ and hMADs progenitors have self-renewal capability, and can thus be expanded. They differentiate, in response to specific agents, into functional brown adipocytes that express high levels of UCP1, are rich in mitochondria, and undergo highly uncoupled cell respiration (Crisan et al., 2008; Elabd et al., 2009). The muscle-derived CD34+ cells differentiate exclusively into brown adipocytes, and do not appear to produce white adipocytes (i.e., not expressing UCP1; Crisan et al., 2008). The WAT-derived hMADs, in contrast, differentiate initially into white adipocytes, and only gain a brown phenotype (UCP1 expression) following an extended exposure to PPAR $\gamma$ activators (rosiglitazone; Elabd et al., 2009). These cell types are thus quite distinct, and each have the potential of generating relevant cell models for studying human brown adipocyte biology as well as screening for anti-obesity therapeutics. Such screens could identify agents that induce the differentiation of the cells into brown adipocytes. Validation that the agents have in fact induced brown adipocyte formation will require analysis of several functional features of BAT. These would include quantitative PCR and western blot analysis of brown-selective/specific genes such as UCP1, CIDEA, and PGC- $1 \alpha$ as well as measurement of cell respiration

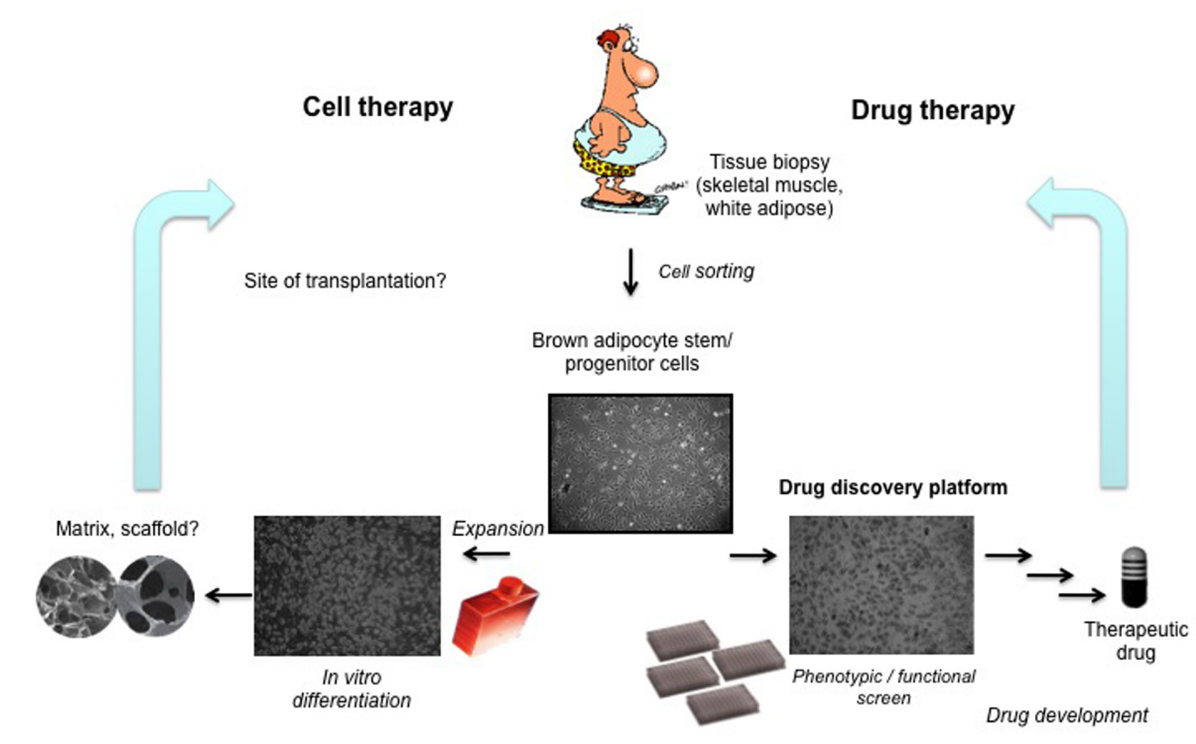

FIGURE 1 |The discovery of brown adipocyte stem/progenitor cells in humans of all ages provides an essential tool for drug discovery. The cells could also be expanded and induced to differentiate in culture, and transplanted back to the patient.
Increasing the amount of brown adipose tissue (through recruitment or transplantation) is expected to improve glucose metabolism (diabetes), lower body fat (obesity), and ameliorate dyslipidemia and cardiovascular disease risks. 
(i.e., $\mathrm{O}_{2}$ consumption) to determine the degree of uncoupling of oxidative phosphorylation. Advantages of phenotypic cellular screens (Swinney and Anthony, 2011) are: (a) there is no need to know upfront the identity of a molecular target or how to affect a particular target (activate, inhibit, or modulate); (b) unsuspected, novel targets, or pathways can be identified based on efficacy in the relevant cellular environment; (c) agents toxic to human cells are eliminated early in the screening process. After a phenotypic screen we know that the active agents reach their molecular target(s), whether it is at the cell surface or inside the cell, and they modify their molecular target(s) in the appropriate way to reach efficacy, whether it is through activation, inhibition, or modulation. Very recently, Schulz et al. (2011) identified brown adipocyte progenitors in skeletal muscle, interscapular BAT, and some white adipose depots of mice. It is too early to know whether these cells represent the mouse equivalents of the human CD34+ and hMADs.

\section{USE OF BROWN ADIPOCYTE PROGENITORS FOR TRANSPLANTATION}

The existence of brown adipocyte stem/progenitor cells that are readily accessible through biopsy of human tissues such as skeletal muscle and subcutaneous WAT encourages the development of transplantation procedures to treat obese, diabetic patients. Harvested cells from tissue biopsies of insulin resistant individuals could be expanded and induced to differentiate into brown adipocytes prior to their implantation as an autologous transplantation to enhance energy expenditure and improve glucose metabolism in obese, insulin resistant patients. In fact, BAT (tissue rather than cells) implants in mice have recently been shown to robustly improve the metabolic condition of obese, insulin resistant mice (Stanford et al., 2011), and more surprisingly, to restore

\section{REFERENCES}

Ailhaud, G., Grimaldi, P., and Negrel, R. (1992). Cellular and molecular aspects of adipose tissue development. Annu. Rev. Nutr. 12, 207-233.

Almind, K., Manieri, M., Sivitz, W. I., Cinti, S., and Kahn, C. R. (2007). Ectopic brown adipose tissue in muscle provides a mechanism for differences in risk of metabolic syndrome in mice. Proc. Natl. Acad. Sci. U.S.A. 104, 2366-2371.

Arch, J. R. (2002). Beta(3)-adrenoceptor agonists: potential, pitfalls and progress. Eur. J. Pharmacol. 440, 99-107.

Arch, J. R. (2008). The discovery of drugs for obesity, the metabolic effects of leptin and variable receptor pharmacology: perspectives from beta3-adrenoceptor agonists. Naunyn Schmiedebergs Arch. Pharmacol. 378, 225-240.

Bar-Shalom, R., Gaitini, D., Keidar, Z., and Israel, O. (2004). Nonmalignant FDG uptake in infradiaphragmatic adipose tissue: a new site of physiological tracer biodistribution characterised by PET/CT.
Eur. J. Nucl. Med. Mol. Imaging 31, 1105-1113.

Boss, O., Samec, S., Paoloni-Giacobino, A., Rossier, C., Dulloo, A., Seydoux, J., Muzzin, P., and Giacobino, J. P. (1997). Uncoupling protein3: a new member of the mitochondrial carrier family with tissuespecific expression. FEBS Lett. 408, 39-42.

Cannon, B., and Nedergaard, J. (2004). Brown adipose tissue: function and physiological significance. Physiol. Rev. 84, 277-359.

Cannon, B., and Nedergaard, J. (2009). Thermogenesis challenges the adipostat hypothesis for body-weight control. Proc. Nutr. Soc. 68, 401-407.

Celi, F. S. (2009). Brown adipose tissue - when it pays to be inefficient. N. Engl. J. Med. 360, 1553-1556.

Christensen, C. R., Clark, P. B., and Morton, K. A. (2006). Reversal of hypermetabolic brown adipose tissue in F-18 FDG PET imaging. Clin. Nucl. Med. 31, 193-196.

Cohade, C., Mourtzikos, K. A., and Wahl, R. L. (2003). “USA-fat": prevalence is related to ambient outdoor

normoglycemia and glucose tolerance in streptozotocin-induced diabetic mice (Piston and Gunawardana, 2011). In addition to acting as a glucose and energy sink, brown adipocytes are likely to also secrete factors (locally and/or in the circulation) that may have beneficial effects on glucose metabolism/insulin sensitivity and overall energy balance. It is indeed probably through this mechanism that BAT affects the "adipostat." Recent studies suggest that the secretome of BAT is quite different from that of WAT since BAT expresses significantly lower levels of resistin and other adipokines associated with insulin resistance (Kajimura et al., 2008; Vernochet et al., 2009). Additionally, these adipokines are suppressed during the conversion of white adipocytes to brown-like cells in WAT during exposure of mice to synthetic PPAR $\gamma$ ligands (Vernochet et al., 2009).

\section{SUMMARY}

From the recent data showing active BAT in adult humans, as well as from animal data, it seems that the most promising strategy for developing therapeutics for obesity and type 2 diabetes is to increase BAT mass, or in fact, restore a healthy level of BAT mass in patients (Figure 1). This new approach should allow the development of effective drugs for obesity, diabetes, and the metabolic syndrome that, unlike diet drugs, are devoid of central side effects.

\section{ACKNOWLEDGMENTS}

We thank Drs. Mihaela Crisan, Erasmus Medical Center, Rotterdam, Netherlands; Jean-Paul Giacobino, University of Geneva Medical Center, Geneva, Switzerland; Scott Gullicksen, Energesis Pharmaceuticals, Inc., Cambridge, MA, USA for essential collaboration and discussions. Cited work from the Farmer laboratory was supported by USPHS grants DK51586, DK58825 and DK86629.

temperature-evaluation with $18 \mathrm{~F}$ FDG PET/CT. J. Nucl. Med. 44, $1267-1270$.

Collins, S., Daniel, K. W., Petro, A. E., and Surwit, R. S. (1997). Strain-specific response to beta 3-adrenergic receptor agonist treatment of diet-induced obesity in mice. Endocrinology 138 , 405-413.

Cousin, B., Bascands-Viguerie, N., Kassis, N., Nibbelink, M., Ambid, L., Casteilla, L., and Penicaud, L. (1996). Cellular changes during cold acclimatation in adipose tissues. J. Cell. Physiol. 167, 285-289.

Cousin, B., Cinti, S., Morroni, M., Raimbault, S., Ricquier, D., Penicaud, L. and Casteilla, L. (1992). Occurrence of brown adipocytes in rat white adipose tissue: molecular and morphological characterization. J. Cell Sci. 103(Pt 4), 931-942.

Crescenzo, R., Samec, S., Antic, V., Rohner-Jeanrenaud, F., Seydoux, J., Montani, J. P., and Dulloo, A. G. (2003). A role for suppressed thermogenesis favoring catch-up fat in the pathophysiology of catch-up growth. Diabetes 52, 1090-1097.

Crisan, M., Casteilla, L., Lehr, L., Carmona, M., Paoloni-Giacobino, A., Yap, S., Sun, B., Leger, B., Logar, A., Penicaud, L., Schrauwen, P., Cameron-Smith, D., Russell, A. P., Peault, B., and Giacobino, J. P. (2008). A reservoir of brown adipocyte progenitors in human skeletal muscle. Stem Cells 26, 2425-2433.

Cypess, A. M., Lehman, S., Williams, G. Tal, I., Rodman, D., Goldfine, A. B., Kuo, F. C., Palmer, E. L., Tseng, Y. H., Doria, A., Kolodny, G. M., and Kahn, C. R. (2009). Identification and importance of brown adipose tissue in adult humans. N. Engl. J. Med. 360, 1509-1517.

Deng, C., Paoloni-Giacobino, A., Kuehne, F., Boss, O., Revelli, J. P., Moinat, M., Cawthorne, M. A., Muzzin, P., and Giacobino, J. P. (1996). Respective degree of expression of beta 1-, beta 2- and beta 3-adrenoceptors in human brown and white adipose tissues. $B r$. J. Pharmacol. 118, 929-934. 
Digby, J. E., Montague, C. T., Sewter, C. P., Sanders, L., Wilkison, W. O., O'Rahilly, S., and Prins, J. B. (1998). Thiazolidinedione exposure increases the expression of uncoupling protein 1 in cultured human preadipocytes. Diabetes 47, 138-141.

Dulloo, A. G. (2005). A role for suppressed skeletal muscle thermogenesis in pathways from weight fluctuations to the insulin resistance syndrome. Acta Physiol. Scand. 184, 295-307.

Dulloo, A. G. (2007). Suppressed thermogenesis as a cause for resistance to slimming and obesity rebound: adaptation or illusion? Int. J. Obes. (Lond.) 31, 201-203.

Dulloo, A. G., and Girardier, L. (1990). Adaptive changes in energy expenditure during refeeding following lowcalorie intake: evidence for a specific metabolic component favoring fat storage. Am. J. Clin. Nutr. 52, 415-420.

Elabd, C., Chiellini, C., Carmona, M., Galitzky, J., Cochet, O., Petersen, R., Penicaud, L., Kristiansen, K., Bouloumie, A., Casteilla, L., Dani, C., Ailhaud, G., and Amri, E. Z. (2009). Human multipotent adiposederived stem cells differentiate into functional brown adipocytes. Stem Cells 27, 2753-2760.

Farmer, S. R. (2009). Obesity: be cool, lose weight. Nature 458, 839-840.

Feldmann, H. M., Golozoubova, V., Cannon, B., and Nedergaard, J. (2009). UCP1 ablation induces obesity and abolishes diet-induced thermogenesis in mice exempt from thermal stress by living at thermoneutrality. Cell Metab. 9, 203-209.

Fukuchi, K., Tatsumi, M., Ishida, Y., Oku, N., Hatazawa, J., and Wahl, R. L. (2004). Radionuclide imaging metabolic activity of brown adipose tissue in a patient with pheochromocytoma. Exp. Clin. Endocrinol. Diabetes 112, 601-603.

Garcia, C. A., Van Nostrand, D., Atkins, F., Acio, E., Butler, C., Esposito, G., Kulkarni, K., and Majd, M. (2006). Reduction of brown fat 2-deoxy2-[F-18]fluoro-D-glucose uptake by controlling environmental temperature prior to positron emission tomography scan. Mol. Imaging Biol. 8, 24-29.

Garcia, C. A., Van Nostrand, D., Majd, M., Atkins, F., Acio, E., Sheikh, A., and Butler, C. (2004). Benzodiazepine-resistant "brown fat" pattern in positron emission tomography: two case reports of resolution with temperature control. Mol. Imaging Biol. 6, 368-372.
Ghorbani, M., and Himms-Hagen, J. (1997). Appearance of brown adipocytes in white adipose tissue during CL 316,243-induced reversal of obesity and diabetes in Zucker $\mathrm{fa} / \mathrm{fa}$ rats. Int. J. Obes. Relat. Metab. Disord. 21, 465-475.

Giordano, A., Morroni, M., Santone, G., Marchesi, G. F., and Cinti, S. (1996). Tyrosine hydroxylase, neuropeptide $\mathrm{Y}$, substance $\mathrm{P}$, calcitonin gene-related peptide and vasoactive intestinal peptide in nerves of rat periovarian adipose tissue: an immunohistochemical and ultrastructural investigation. J. Neurocytol. 25, 125-136.

Granneman, J. G., Li, P., Zhu, Z., and Lu, Y. (2005). Metabolic and cellular plasticity in white adipose tissue I: effects of beta3-adrenergic receptor activation. Am. J. Physiol. Endocrinol. Metab. 289, E608-E616.

Guerra, C., Koza, R. A., Yamashita, H. Walsh, K., and Kozak, L. P. (1998). Emergence of brown adipocytes in white fat in mice is under genetic control. Effects on body weight and adiposity. J. Clin. Invest. 102, 412-420.

Hamann, A., Flier, J. S., and Lowell, B. B. (1996). Decreased brown fat markedly enhances susceptibility to diet-induced obesity, diabetes, and hyperlipidemia. Endocrinology 137, 21-29.

Hany, T. F., Gharehpapagh, E., Kamel, E. M., Buck, A., Himms-Hagen, J., and Von Schulthess, G. K. (2002). Brown adipose tissue: a factor to consider in symmetrical tracer uptake in the neck and upper chest region. Eur. J. Nucl. Med. Mol. Imaging 29, 1393-1398.

Harper, M.-E., Dent, R., Tesson, F., and Mcpherson, R. (2004). "Targeting thermogenesis in the development of antiobesity drugs," in Pharmacotherapy of Obesity: Options and Alternatives, eds K. G. Hofbauer, U. Keller, and O. Boss (Boca Raton, FL: CRC Press), 363-383.

Heaton, J. M. (1972). The distribution of brown adipose tissue in the human. J. Anat. 112, 35-39.

Heilbronn, L. K., and Ravussin, E. (2003). Calorie restriction and aging: review of the literature and implications for studies in humans. Am. J. Clin. Nutr. 78, 361-369.

Himms-Hagen, J., Cui, J., Danforth, E. Jr., Taatjes, D. J., Lang, S. S., Waters, B. L., and Claus, T. H. (1994). Effect of CL-316243, a thermogenic beta 3-agonist, on energy balance and brown and white adipose tissues in rats. Am. J. Physiol. 266, R1371R1382.
Himms-Hagen, J., Melnyk, A., Zingaretti, M. C., Ceresi, E., Barbatelli, G., and Cinti, S. (2000). Multilocular fat cells in WAT of CL-316243treated rats derive directly from white adipocytes. Am. J. Physiol. Cell Physiol. 279, C670-C681.

Holloway, B. R., Howe, R., Rao, B. S., and Stribling, D. (1992). ICI D7114: a novel selective adrenoceptor agonist of brown fat and thermogenesis. Am. J. Clin. Nutr. 55, 262S-264S.

Huttunen, P., Hirvonen, J., and Kinnula, V. (1981). The occurrence of brown adipose tissue in outdoor workers. Eur. J. Appl. Physiol. Occup. Physiol. 46, 339-345.

Jimenez, M., Barbatelli, G., Allevi, R. Cinti, S., Seydoux, J., Giacobino, J. P., Muzzin, P., and Preitner, F. (2003). Beta 3-adrenoceptor knockout in C57BL/6J mice depresses the occurrence of brown adipocytes in white fat. Eur. J. Biochem. 270, 699-705.

Kajimura, S., Seale, P., Tomaru, T. Erdjument-Bromage, H., Cooper, M. P., Ruas, J. L., Chin, S., Tempst, P., Lazar, M. A., and Spiegelman, B. M. (2008). Regulation of the brown and white fat gene programs through a PRDM16/CtBP transcriptional complex. Genes Dev. 22, 1397-1409.

Kim, H., Pennisi, P. A., Gavrilova, O., Pack, S., Jou, W., Setser-Portas, J., East-Palmer, J., Tang, Y., Manganiello, V. C., and Leroith, D. (2006). Effect of adipocyte beta3adrenergic receptor activation on the type 2 diabetic MKR mice. Am. J. Physiol. Endocrinol. Metab. 290, E1227-E1236.

Klaus, S., Ely, M., Encke, D., and Heldmaier, G. (1995). Functional assessment of white and brown adipocyte development and energy metabolism in cell culture. Dissociation of terminal differentiation and thermogenesis in brown adipocytes. J. Cell Sci. 108(Pt 10), 3171-3180.

Kopecky, J., Baudysova, M., Zanotti, F., Janikova, D., Pavelka, S., and Houstek, J. (1990). Synthesis of mitochondrial uncoupling protein in brown adipocytes differentiated in cell culture. J. Biol. Chem. 265, 22204-22209.

Kopecky, J., Clarke, G., Enerback, S. Spiegelman, B., and Kozak, L. P. (1995). Expression of the mitochondrial uncoupling protein gene from the aP2 gene promoter prevents genetic obesity. J. Clin. Invest. 96, 2914-2923.

Kopecky, J., Hodny, Z., Rossmeisl, M., Syrovy, I., and Kozak, L. P. (1996a). Reduction of dietary obesity in aP2Ucp transgenic mice: physiology and adipose tissue distribution. Am. J. Physiol. 270, E768-E775.

Kopecky, J., Rossmeisl, M., Hodny, Z., Syrovy, I., Horakova, M., and Kolarova, P. (1996b). Reduction of dietary obesity in aP2-Ucp transgenic mice: mechanism and adipose tissue morphology. Am. J. Physiol. 270, E776-E786.

Kozak, L. P., and Koza, R. A. (1999). Mitochondria uncoupling proteins and obesity: molecular and genetic aspects of UCP1. Int. J. Obes. Relat. Metab. Disord. 23(Suppl. 6), S33S37.

Lean, M. E., James, W. P., Jennings, G., and Trayhurn, P. (1986). Brown adipose tissue in patients with pheochromocytoma. Int. J. Obes. 10, 219-227.

Leibel, R. L., Rosenbaum, M., and Hirsch, J. (1995). Changes in energy expenditure resulting from altered body weight. N. Engl. J. Med. 332, 621-628.

Loncar, D. (1991a). Convertible adipose tissue in mice. Cell Tissue Res. 266, 149-161.

Loncar, D. (1991b). Development of thermogenic adipose tissue. Int. J. Dev. Biol. 35, 321-333.

Lowell, B. B., V, S. S., Hamann, A., Lawitts, J. A., Himms-Hagen, J., Boyer, B. B., Kozak, L. P., and Flier, J. S. (1993). Development of obesity in transgenic mice after genetic ablation of brown adipose tissue. Nature 366, 740-742.

Major, G. C., Doucet, E., Trayhurn, P., Astrup, A., and Tremblay, A. (2007). Clinical significance of adaptive thermogenesis. Int. J. Obes. (Lond.) 31, 204-212.

Mattsson, C. L., Csikasz, R. I., Chernogubova, E., Yamamoto, D. L., Hogberg, H. T., Amri, E. Z., Hutchinson, D. S., and Bengtsson, T. (2011). Betal-adrenergic receptors increase UCP1 in human MADS brown adipocytes and rescue cold-acclimated beta3-adrenergic receptor-knockout mice via nonshivering thermogenesis. Am. J. Physiol. Endocrinol. Metab. 301, E1108-E1118.

Nagase, I., Yoshida, T., Kumamoto, K., Umekawa, T., Sakane, N., Nikami, H., Kawada, T., and Saito, M. (1996). Expression of uncoupling protein in skeletal muscle and white fat of obese mice treated with thermogenic beta 3-adrenergic agonist. J. Clin. Invest. 97, 2898-2904.

Nedergaard, J., Bengtsson, T., and Cannon, B. (2007). Unexpected evidence for active brown adipose tissue in adult humans. Am. J. Physiol. Endocrinol. Metab. 293, E444-E452. 
Orci, L., Cook, W. S., Ravazzola, M., Wang, M. Y., Park, B. H., Montesano, R., and Unger, R. H. (2004). Rapid transformation of white adipocytes into fat-oxidizing machines. Proc. Natl. Acad. Sci. U.S.A. 101, 2058-2063.

Petrovic, N., Walden, T. B., Shabalina, I. G., Timmons, J. A., Cannon, B., and Nedergaard, J. (2010). Chronic peroxisome proliferator-activated receptor gamma (PPARgamma) activation of epididymally derived white adipocyte cultures reveals a population of thermogenically competent, UCP1-containing adipocytes molecularly distinct from classic brown adipocytes. J. Biol. Chem. 285, 7153-7164.

Piston, D. W., and Gunawardana, S. C. (2011). "Reversal of type 1 diabetes by brown adipose tissue transplant," in American Diabetes Association Scientific Sessions, San Diego, CA.

Ramacciotti, C., Schneegans, O., Lang, H., Lindner, V., Claria, M., Moreau, F., Chenard, M. P., Pinget, M., and Kessler, L. (2006). Diffuse uptake of brown fat on computed-tomography coupled positron emission tomoscintigraphy (PET-CT) for the exploration of extra-adrenal pheochromocytoma. Ann. Endocrinol. (Paris) 67, 14-19.

Ravussin, E., and Kozak, L. (2004). "Energy homeostasis," in Pharmacotherapy of Obesity: Options and Alternatives, eds K. G. Hofbauer, U. Keller, and O. Boss (Boca Raton, FL: CRC Press), 3-23.

Rehnmark, S., Nechad, M., Herron, D., Cannon, B., and Nedergaard, J. (1990). Alpha- and beta-adrenergic induction of the expression of the uncoupling protein thermogenin in brown adipocytes differentiated in culture. J. Biol. Chem. 265, 16464-16471.

Ricquier, D., Nechad, M., and Mory, G. (1982). Ultrastructural and biochemical characterization of human brown adipose tissue in pheochromocytoma. J. Clin. Endocrinol. Metab. 54, 803-807.
Rodeheffer, M. S., Birsoy, K., and Friedman, J. M. (2008). Identification of white adipocyte progenitor cells in vivo. Cell 135, 240-249.

Rothwell, N. J., and Stock, M. J. (1979). A role for brown adipose tissue in diet-induced thermogenesis. Nature 281, 31-35.

Saito, M., Okamatsu-Ogura, Y., Matsushita, M., Watanabe, K., Yoneshiro, T., Nio-Kobayashi, J., Iwanaga, T., Miyagawa, M., Kameya, T., Nakada, K., Kawai, Y., and Tsujisaki, M. (2009). High incidence of metabolically active brown adipose tissue in healthy adult humans: effects of cold exposure and adiposity. Diabetes 58, 1526-1531.

Schulz, T. J., Huang, T. L., Tran, T. T., Zhang, H., Townsend, K. L., Shadrach, J. L., Cerletti, M., Mcdougall, L. E., Giorgadze, N., Tchkonia, T., Schrier, D., Falb, D., Kirkland, J. L., Wagers, A. J., and Tseng, Y. H. (2011). Identification of inducible brown adipocyte progenitors residing in skeletal muscle and white fat. Proc. Natl. Acad. Sci. U.S.A. 108, 143-148.

Seale, P., Bjork, B., Yang, W., Kajimura, S., Chin, S., Kuang, S., Scime, A., Devarakonda, S., Conroe, H. M. Erdjument-Bromage, H., Tempst, P., Rudnicki, M. A., Beier, D. R., and Spiegelman, B. M. (2008). PRDM16 controls a brown fat/skeletal muscle switch. Nature 454, 961-967.

Soloveva, V., Graves, R. A., Rasenick, M. M., Spiegelman, B. M., and Ross, S. R. (1997). Transgenic mice overexpressing the beta 1-adrenergic receptor in adipose tissue are resistant to obesity. Mol. Endocrinol. 11, 27-38.

Stanford, K. I., Middelbeek, R. J. W., An, D., Townsend, K. L., Hitchcox, K. M., Jung, D. Y., Lee, Y. J., Kim, J. K., Hirshman, M. F., Tseng, Y. H., and Goodyear, L. J. (2011). "Transplantation of brown adipose tissue exerts beneficial effects on glucose homeostasis," in American Diabetes Association Scientific Sessions, San Diego.
Stylopoulos, N., Hoppin, A. G., and Kaplan, L. M. (2009). Roux-en$\mathrm{Y}$ gastric bypass enhances energy expenditure and extends lifespan in diet-induced obese rats. Obesity (Silver Spring) 17, 1839-1847.

Swinney, D. C., and Anthony, J. (2011). How were new medicines discovered? Nat. Rev. Drug Discov. 10, 507-519.

Tang, W., Zeve, D., Suh, J. M. Bosnakovski, D., Kyba, M., Hammer, R. E., Tallquist, M. D., and Graff, J. M. (2008). White fat progenitor cells reside in the adipose vasculature. Science 322, 583-586.

Tseng, Y. H., Kokkotou, E., Schulz, T. J., Huang, T. L., Winnay, J. N., Taniguchi, C. M., Tran, T. T., Suzuki, R., Espinoza, D. O., Yamamoto, Y. Ahrens, M. J., Dudley, A. T., Norris, A. W., Kulkarni, R. N., and Kahn, C. R. (2008). New role of bone morphogenetic protein 7 in brown adipogenesis and energy expenditure. Nature 454, 1000-1004.

Van Marken Lichtenbelt, W. D., Vanhommerig, J. W., Smulders, N. M., Drossaerts, J. M., Kemerink, G. J., Bouvy, N. D., Schrauwen, P., and Teule, G. J. (2009). Coldactivated brown adipose tissue in healthy men. N. Engl. J. Med. 360, 1500-1508.

Vernochet, C., Peres, S. B., Davis, K. E., Mcdonald, M. E., Qiang, L., Wang, H., Scherer, P. E., and Farmer, S. R. (2009). C/EBPalpha and the corepressors CtBP1 and $\mathrm{CtBP} 2$ regulate repression of select visceral white adipose genes during induction of the brown phenotype in white adipocytes by peroxisome proliferator-activated receptor gamma agonists. Mol. Cell. Biol. 29, 4714-4728.

Wilson-Fritch, L., Nicoloro, S. Chouinard, M., Lazar, M. A., Chui, P. C., Leszyk, J., Straubhaar, J., Czech, M. P., and Corvera, S. (2004). Mitochondrial remodeling in adipose tissue associated with obesity and treatment with rosiglitazone. J. Clin. Invest. 114, 1281-1289.
Xue, B., Coulter, A., Rim, J. S., Koza, R. A., and Kozak, L. P. (2005). Transcriptional synergy and the regulation of Ucp1 during brown adipocyte induction in white fat depots. Mol. Cell. Biol. 25, 8311-8322.

Yoneshiro, T., Aita, S., Matsushita, M., Kameya, T., Nakada, K., Kawai, Y., and Saito, M. (2011). Brown adipose tissue, whole-body energy expenditure, and thermogenesis in healthy adult men. Obesity (Silver Spring) 19, 13-16.

Young, P., Arch, J. R., and Ashwell, M. (1984). Brown adipose tissue in the parametrial fat pad of the mouse. FEBS Lett. 167, 10-14.

Zingaretti, M. C., Crosta, F., Vitali, A., Guerrieri, M., Frontini, A. Cannon, B., Nedergaard, J., and Cinti, S. (2009). The presence of UCP1 demonstrates that metabolically active adipose tissue in the neck of adult humans truly represents brown adipose tissue. FASEB J. 23, 3113-3120.

Conflict of Interest Statement: The authors declare that the research was conducted in the absence of any commercial or financial relationships that could be construed as a potential conflict of interest.

Received: 06 December 2011; paper pending published: 27 December 2011; accepted: 17 January 2012; published online: 06 February 2012.

Citation: Boss $O$ and Farmer $S R$ (2012) Recruitment of brown adipose tissue as a therapy for obesity-associated diseases. Front. Endocrin. 3:14. doi: 10.3389/fendo.2012.00014

This article was submitted to Frontiers in Cellular Endocrinology, a specialty of Frontiers in Endocrinology.

Copyright $(\mathrm{C}) 2012$ Boss and Farmer. This is an open-access article distributed under the terms of the Creative Commons Attribution Non Commercial License, which permits non-commercial use, distribution, and reproduction in other forums, provided the original authors and source are credited. 